\title{
Article
}

\section{To Tweet Or Not To Tweet: Is That Really The Question?}

\author{
Danino, Nicky
}

Available at http://clok.uclan.ac.uk/27821/

Danino, Nicky ORCID: 0000-0001-7662-9188 (2019) To Tweet Or Not To Tweet: Is That Really The Question? INTED Conference Published Proceedings . pp. 7081-7087. ISSN 2340-1079

It is advisable to refer to the publisher's version if you intend to cite from the work.

For more information about UCLan's research in this area go to

http://www.uclan.ac.uk/researchgroups/ and search for <name of research Group>.

For information about Research generally at UCLan please go to

http://www.uclan.ac.uk/research/

All outputs in CLoK are protected by Intellectual Property Rights law, including Copyright law. Copyright, IPR and Moral Rights for the works on this site are retained by the individual authors and/or other copyright owners. Terms and conditions for use of this material are defined in the policies page.

\section{CLoK}

Central Lancashire online Knowledge www.clok.uclan.ac.uk

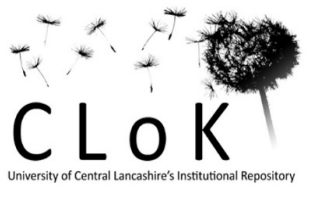




\title{
TO TWEET OR NOT TO TWEET: IS THAT REALLY THE QUESTION?
}

\author{
N. Danino \\ University of Central Lancashire (UNITED KINGDOM)
}

\begin{abstract}
This research consists of a longitudinal study conducted with students on computer science courses to investigate whether Twitter can be an effective tool for use in teaching computer science in higher education. The inspiration for this work is fuelled by the differing anecdotal opinions of colleagues, together with the recent surge of popular interest in Twitter as a micro-blogging tool, especially in education. The aims of this work are to analyse the Twitter usage habits of computer science students, specifically, how they use Twitter to enter and engage in dialogue, and the issues that might arise from this. This research focuses specifically on the conceivable possibilities presented by Twitter for use as a teaching and learning tool.
\end{abstract}

Initially, a survey was conducted to gather a breadth of the data on usage habits. This was followed by data mining on Twitter that consisted of harvesting behavioural data from the micro-blogging platform over a period of 3 years. The initial results presented in this work point to the potential of using Twitter as a pedagogy tool. Some downfalls are also highlighted such as Twitter's conceivable role as a distractor. Results suggests that it is still too early to determine whether Twitter can be an effective pedagogical tool, nonetheless, the scope for future work points towards many possibilities for further research and application.

Keywords: Social Media, Computer Mediated Communication, Twitter, Social Interaction, Education

\section{INTRODUCTION}

'Social Media' is a ubiquitous expression that has become intrinsically linked to websites such as Facebook, Flickr, YouTube, Twitter, and Instagram. Using the word 'social' to describe such media suggests that it is situated in a social space where users interact in some way with said media. Social Media is defined by Kaplan and Haenlein (2010: p61) as "a group of Internet-based applications that build on the ideological and technological foundations of Web 2.0 and that allow the creation and exchange of user-generated content'. Tess (2013) substantiates that definition by defining the space as one which allows collaboration and community. Although he also points out that today's social media applications are in a constant state of change, and therefore quite hard to define.

A reasonable assumption to make would be that computer science educators would be abundant on social media, and likewise, would be applying the technology in the classroom. However, several studies have shown that integrating social media in teaching presents several challenges [1], [2].

The paper focusses on understanding the experiences of Computer Science academics with Twitter those who have responsibility for delivering teaching, learning and assessment - at a single higher education institution in the UK. It also focusses on the experience of Computer Science students at the same institution.

This research was motivated, primarily, by the anecdotal evidence that university students are spending more and more time online and connecting via social media networks, especially out of the classroom. Furthermore, the inspiration for this work was fuelled by the lack of specific frameworks, together with the recent surge of popular interest in Twitter as a micro-blogging tool, especially in education [3].

As a practitioner-researcher in computer science and with an interest in social media usage, I am interested in knowing more about how the flow of dialogue and communication for students is constructed, both socially and academically, with Twitter as the vehicle.

\section{BACKGROUND AND RELATED WORK}

Before expanding on the theoretical foundation of this study, it makes sense to understand where Twitter is situated. 
At the time of writing, Twitter has over 326 million active monthly users, tweeting more than 500 million tweets per day. Whilst Twitter was not the first micro-blogging platform, and is certainly not the only one in existence, it is, by far, the most popular. Indeed, the name Twitter is in most instances used as a pseudonym for micro-blogging, and the word "tweet" as both a noun and a verb has now entered the English lexicon.

Although Twitter can be used as an announcement channel, the dialogic nature of Twitter and its capacity to enable dialogue, discussion and communication has markedly added to its popularity [4]. Twitter allows users to create pathways so that messages can be directed toward one person (@), be privately viewed (DM), or be retweeted (RT), i.e. shared with others. Honeycutt and Herring [5] examine several of the ways in which Twitter can be used, which they refer to as "categories of intention". These classifications incorporate everyday conversation, distributing knowledge or website addresses, broadcasting news, and dialogue. It comes as no surprise that educators are showing an interest in using Twitter in the classroom, given its rising acceptance and tractability.

Research has shown that universities are somewhat poor at using dialogic features in their websites [6]. However, there is little evidence to suggest that universities have seriously approached their use of Social Media in a dialogic context. Within education, Twitter can be used to enhance social interaction, with strong instructional value [7]. According to Junco et al [8] the use of Twitter can be used as a motivator, when applied within a course. Dunlap and Lowenthal [7] state the importance of social presence amongst staff and students, highlighting the significance of that feeling that another person is there and real, in a community of learners where people connect in a social and emotional way through the communication medium. A position supported by Vygotsky [9] who emphasises the importance of creating social communities, which lead to learning at a higher cognitive processing level.

Short et al. devised the expression 'social presence' in 1976 [10], with work that was based on research, centered on one-to-one interpersonal communication. Their social presence theory catalogues various types of communication along a scale, somewhat on the level of awareness that someone feels towards others in the communication. However, changes in types of communications, since 1976, have had an effect on this definition, which has had to evolve with time. More recently, literature has emerged that offers findings about how communication is carried out online, and how it is interpreted [11]. This has been especially important due to the advent of online learning courses. According to Kanwar and Swenson [12], socialisation can be defined as the "process by which people learn the characteristics of their group and the attitudes, values, and actions thought appropriate for them" (p. 18). Jacobson [13] explains presence as the sense of being caught up in the representation of virtual worlds. Considering these meanings, it can be comprehended how the student's awareness of presence could have an influence on their motivation to both socialise with other students, and the level to which they interact with their education online.

The importance of emotional issues surrounding education is demonstrated clearly by the work of Mavrikis, Maciocia and Lee [14], who state that it is difficult to develop educational systems that take sentiments into account because of the "pervasive influences of affective factors" but mostly "due to the existence of various, usually contradictory theories" (p. 1). As online educational scenarios become more widespread, educators are starting to recognise that creating social presence is becoming key to creating more successful teaching environments. This is epecially true in Higher Education, where students have less online restrictions than school or colleges.

This social community aspect can be achieved via experiential learning, as students are engaged with their course material, as opposed to just thinking about what they are learning and repeating the knowledge. Kolb [15] explains learning as the "process whereby knowledge is created through transformative experience" (p. 41).

Notwithstanding the absence of empirical work concerning the use of Twitter in a Higher Education setting points to some common notions of its use. Chiefly, the conceivable advantages of Twitter, to nurture an awareness of community both inside and outside the classroom, are recognisable. Literature points to the social advantages of social media [4], [16] including Twitter [17], in connecting educators with students, and students with other students.

\section{METHODOLOGY}

This research is inter-disciplinary, in the sense that the subject matter and research processes straddle the disciplines of education and computing science. Additionally, the work grouped under 'social media research' is also vastly interdisciplinary and consequently the methodological approaches that are 
applied in this field are similarly broad and diverse. Therefore, I am approaching this research by embracing a mixed methods approach.

Both Bryman [18] and Creswell and Plano Clark [19] reason that mixing qualitative and quantitative methods brings together the advantages of each while diminishing their particular limitations. For example, I plan on carrying out an online survey with staff and students. I chose to use a computerbased questionnaire for two reasons. The first was to lessen the time and work necessary to manage the gathering of data. The second reason was that participants occasionally generate illegible responses in paper-based questionnaires. Using a computer-based questionnaire removes the response error, as participants enter the values via typing on a keyboard instead. Furthermore computer-based questionnaires can be programmed to compel the participant to input a response before going on to the subsequent question, and checks that the answers entered lie inside a specific scope.

Online-based questionnaires are seen as a cheaper substitute to paper, and can be completed by more people, in more places. A comparison research study by Petitt [20] highlighted that there are no discernible differences between the two modes of questionnaire data gathering. In fact, the paper-based mode experienced a higher number of statistical errors.

This will be followed by data mining on Twitter that will consist of harvesting information from the microblogging platform. Traditionally, researchers carrying out qualitative research have coded data using paper and possible a range of coloured pens. Each code is a label or category that may be applied to further data. Using QSR NVivo 12 I can work through exactly the same process of coding, but each code is represented as a node that contains all the data that I assign to that code. I will begin the process of making sense of the data by creating nodes (codes) in NVivo. I will then try to make sense of the nodes by grouping them into what I think are logical alignments and look at word frequency. Additionally, I will also use NVivo to carry out a sentiment analysis. Sentiment analysis has been used by researchers to try and yield meaningful information from tweets [21], [22]. NVivo can be used to search for expressions of sentiment in the source material. It looks at the sentiment of words in isolation - the context is not taken into account. This process uses a scoring system where each word containing sentiment has a pre-defined score. Each sentiment represents a range on that scale. The score for each word determines the sentiment node it is coded to. The score of words can change if they are preceded by a modifier (for example, more or somewhat) which intensifies the sentiment or negated (e.g. not). The auto coder has built-in lexicons for positive and negative sentiments.

Both data collection methods will produce qualitative data and may also result in quantitative data about certain aspects of Twitter use.

Particular consideration was given to ensure that all participants were comfortable taking part in this research. The growing use of Social Media tools highlight specific ethical concerns for research in this area as well as a call for revisiting current ethical approaches to research [23], [24].

All students who directly participated in the research were asked for their consent. However, Tweets were harvested systematically from the public stream and it was not possible to obtain informed consent from all subjects. Tweets are created in the public space of the Web therefore Tweets are public by default, though users can protect their Tweets by making them available only to their followers. Nonetheless, interactions in Social Media often have an ephemeral appeal. This adds to the expectation about information being protected. People can be disposed to supply personal and sensitive information to an online medium, which in principle is accessible for anyone - without intending their statements to be distributed.

There were no assumptions made about the safety of the users. All data was considered sensitive, regardless of whether it had already been released into the public domain by the user, and was made anonymous so that the user could not be identified. Disassociating Twitter names and email addresses with Tweets enabled this anonymity.

\section{RESULTS}

\subsection{Results of the survey}

I used a semi-structured Likert-scale survey method to create a questionnaire using LimeSurvey and hosted it on a server. This was sent out to 150 Computer Science students, yielding 60 responses. However, 6 of these were incomplete, with no data input, and were removed from the final results. It is likely that these were search engines that had crawled to the website or possible 'bots' (web software 
applications that run automated tasks over the Internet). Therefore, the survey results derived from 54 real participants. The aim of this survey was to glean general information about the social media habits of Computer Science students, focusing on their Twitter usage, to answer the research questions posed in this thesis.

Of the 54 participants, $28 \%$ were female, and $72 \%$ male. The average age of the participants was 22.57 years, with the youngest being 18 and the oldest 52 . All of them claimed to be part of a social media community. $43 \%$ of them selected Facebook as their social community of choice, $39 \%$ Twitter, $11 \%$ Linkedln, 2\% MySpace, 3\% GooglePlus, and 2\% Tumblr. These statistics do not come as a surprise to me, after trying to use social media for pedagogy reasons, I am aware that many students use social networking sites on a regular basis. Amongst the reasons given for using social media communities, the most common ones were social-related, such as keeping up with friends, arranging social events and generally communicating with others. This is of particular interest to this research, as the literature has already shown that students that are socially amalgamated with their peers tend to also become academically engaged with them. $76 \%$ of the participants state they use Twitter, with $26 \%$ of them accessing Twitter 5 times or more each day. Therefore, if $76 \%$ of students are already using Twitter, this statistic is of most relevance to this research as it shows there is certainly scope for the use of this social media tool at University to further engage students into academic discussions. In terms of sharing information, $15 \%$ of the participants used Twitter all the time, $48 \%$ used it quite often or sometimes, whilst the rest never use Twitter to share information. This also points to some opportunities for the use of Twitter as a teaching tool, for sharing information, but maybe even also for requesting information from others. When asked if they agree with the statement "I use Twitter to connect with other people", $15 \%$ of participants said they use it all the time and a further $22 \%$ said they use it quite often, $31 \%$ claimed they use Twitter sometimes and the final 13\% answered never. Again, there is an opportunity for creating interaction here, with the majority of participants clearly reaching out via Twitter to some extent. Likewise, $7 \%$ of participants said "I use Twitter to meet new people all the time" and $6 \%$ did this quite often, $35 \%$ did this sometimes, and $33 \%$ never did this. Whilst this is interesting and shows that there may be less opportunity to use Twitter for students to create dialogues with others that may be able to debate and interact with them about their academic subject, it does not impact the interaction amongst classmates, as they will already have met in real life. It should be noted that if Twitter is used in distance learning classes, I advise that the tutor initiate introductions, as students are evidently highlighting that reaching out to strangers on Twitter is not something that they do by default.

One statistic that stood out from the survey was the concept of entertainment. $89 \%$ of students claimed to use Twitter to "pass the time", to some degree. $83 \%$ of them also claimed to use it for entertainment. This points to using Twitter as a distraction, something to do "because it's there".

The snapshot of data I have presented here suggests that there are certain factors that influence patterns of Twitter usage amongst Computer Science students. The relationship between Twitter usage and academia seems to exist atop a web of social relationships, fuelled by the students who use Twitter. It seems that the more students that use it socially, the more their friends use it too, and the more prospects there are for some of that social dialogue to transfer into academic dialogue. The implications for this research are that a tutor has to endorse social engagement within their student cohort and deliver a channel through which students can engage socially, as well as academically. However, there may be a fine line between Twitter as a scaffold for academic dialogue, and Twitter as a distractor. This is an interesting juxtaposition that I need to investigate further.

\subsection{Initial analysis of tweets}

The data mined from Twitter is a correlation of tweets from those four weeks in 2016, 2017 and 2018 with an average of 158 students enrolled each year. The Twitter data mining is part of a longitudinal study, and therefore the results presented here have been collected over a period of three years. In Year 1 of all Computing courses at the University of Central Lancashire, all students have to undertake a four week full-time module at the beginning of their course in September, acting as an introduction to university life and their studies in general [25]. This is designed around an Agile team-based project, intended to foster teamwork and collaboration. The other five modules are delivered concurrently over the subsequent twenty-two weeks of teaching, and each build upon themes introduced in the first module.

A common hashtag (\#computing4WC) was used in order to find and sort tweets more effectively. This hastag was introduced to students in the first week, and they were encouraged to tweet as both teams 
and individuals. Three of the teaching team members also tweeted along with the students to help get the students started, but as the four weeks drew to a close and momentum built, students became more interested in talking with each other and sharing opinions, comments, and information.

Processing tweets is a different method to that of text in articles, books, or even spoken language. Tweets may contain many idiosyncratic uses, such as smileys, links, RT for re-tweet, @ for user mentions and \# for hashtags. In order to analyse this data, increase accuracy and reduce errors, it is essential to clean it up and normalise it.

The total number of viable tweets collected over the three iterations of the module is 3127 . The tweets also elicited 870 replies and 1493 retweets. As expected, the most popular keyword was 'computing4wc', closely followed by 'twitter' and 'media'. These last two keywords have been excluded from the data analysis as they are both words that are inserted by Twitter when any media is attached to a tweet, for example an image or a video clip. The keyword 'twimg' also appears very frequently, in fact, 1268 times. This is actually the result of a tweet containing an image, which is not directly captured as part of the data mining. The term 'jpg' also appeared a similar number of times, so both have been excluded from the word cloud as they are not words that have been typed by students, but rather file names of attached images.

A word cloud of the content of the tweets highlighted the following words as frequent in the discussion: computing4wc, uclan, swipemediaa2, good, team, follow, time, working, nickydanino (Fig. 1). 'computing4wc' and 'uclan' were predominantly used as hashtags, 'swipemediaa2' and 'nickydanino' are user names, whilst the rest were words used in tweet content.

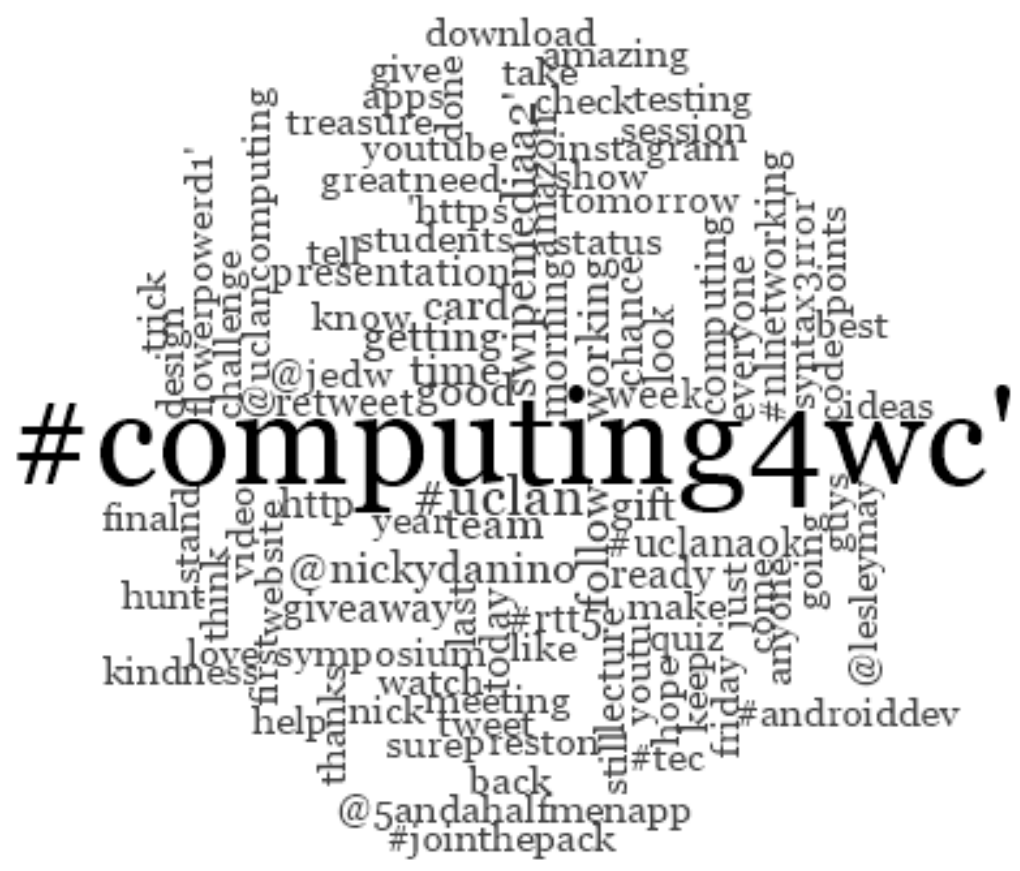

Figure 1. Word cloud of tweets from data mining experiment

An initial sentiment analysis was carried out to garner a wider view of the general feel from staff and students regarding the module, and the use of Twitter within it. This paper's approach classifies the sentiment of each tweet to be either "positive", "negative" or neutral. This is known as a three-way sentiment classification.

The sentiment analysis on the tweets shows that $26.7 \%$ of tweets were positive, with $13.8 \%$ being very positive. Therefore, the analysis also shows that $64.8 \%$ of the tweets were neutral, i.e. they did not show sentiment one way or the other. However, $8.5 \%$ of tweets were negative, with $3.8 \%$ being very negative. As NVivo does not capture sarcasm, double negatives, slang, dialect variations, idioms or ambiguity, there was a need for some manual coding and checking before the initial pass of the sentiment analysis could be completed.

Generally, the sentiment analysis shows that students are either positive or neutral. A closer look at the tweets shows that mostly, the negative tweets are those oriented towards banter between teams, tongue 
in cheek comments, and playful competitive behaviour amongst the teams. For example' Actually terrified about what's going on in there... \#computing4WC < Jason> pic.twitter.com/Al8u5IhUaO' is a comment referring to a photo showing students working late into the night in a computer room. '@jedw @lesleymay there's a bit of a queue for stand up meetings, with 3 groups waiting ahead of us, should we go to the rescue mission then come back to stand up or? \#Computing4WC' is referring to a meeting schedule that is running late, which the students already knew about, and started having a conversation on Twitter with other teams regarding the lateness of the appointments...' Tell us about it, been here since 9:45 waiting \#computing4WC \#pissed'. Although generally these comments are seen as negative, they still show engagement with the process.

\section{CONCLUSIONS}

Initial findings from the data collected shows that the use of Twitter as a pedagogy tool will be far more successful and accepted by both staff and students if integrated within classes. There is a need to establish relevance for students; Twitter use for academic dialogue needs to have a clear purpose to engage students personally, professionally, and in academically meaningful ways.

The results also show that many of the students are consumers of Twitter, and tend to read, but not always engage and contribute. In future, I think that I will increase Twitter in-class sharing of information, especially during lectures. I believe that I could have more students engaging with the lecture material. Ideally, I would like to find a way for me to interact with their tweets on Twitter itself during the lecture. That's obviously difficult if I am teaching at the same time, but if I could be joined by a colleague, or be allocated a teaching assistant, it may be possible and make for a more prolific interaction. This was particularly successful during this study when there was more than one academic in the room.

I also like the idea of using Twitter to maintain ongoing relationships, both between my students and myself and between the students themselves. This is especially practically for classes where I only see students once a week, and also during the holiday period. It will allow me to continue to advise students academically and professionally. It will also permit for a much more usual and organic development of our relationships; rather than dissolving our connections at the end of the semester, we are able to remain in a community with each other, learning and sharing our experiences.

\subsection{Future work}

Twitter as an incredible instrument for education. I encourage other colleagues to instigate testing with Twitter in their classroom. Nonetheless, more structured and rigorous research need to be carried out to categorically evaluate the value of using Twitter in the classroom as well as its relationship to teaching and learning.

There are other directions that can be pursued as an extension of this research. Exploring the influence of social networking on online versus conventional student academic performance and motivation could be interesting. Also, research into whether academic performance has any impact on student behaviour in the social media space both inside and outside the classroom could be noteworthy.

For my own personal interest, I am particularly drawn to how Twitter can also be a distractor, and disengage students, as well as engage them. This point has been specifically featured when I explored the issues that might arise with the use of Twitter in the classroom. I feel that as more digital natives enter Higher Education, this is an area worthy of further research. As I have emphasized in the literature, student engagement is an aspect of Higher Education that has been highlighted in recent years, especially as it is seen as linked with student retention. For me, being able to engage students in their learning, is a step forward towards enabling students to maintain their enthusiasm for their subject, successfully finish their course and embark on an upwards learning journey.

\section{ACKNOWLEDGEMENTS}

I'd like to thank the School of Physical Sciences and Computing at the University of Central Lancashire for funding this research. I'd also like to thank all the staff and student participants in the project.

\section{REFERENCES}

[1] S. Manca and M. Ranieri, 'Is Facebook still a suitable technology-enhanced learning environment? An updated critical review of the literature from 2012 to 2015', J. Comput. Assist. 
Learn., vol. 32, no. 6, pp. 503-528, 2016.

[2] T. Rashid and H. M. Asghar, 'Technology use, self-directed learning, student engagement and academic performance: Examining the interrelations', Comput. Human Behav., vol. 63, pp. 604612, 2016.

[3] A. Fumero-reverón, 'Irc 2.0.', pp. 605-610, 2011.

[4] R. Junco, G. Heiberger, and E. Loken, 'The effect of Twitter on college student engagement and grades', Comput. Human Behav., vol. 28, no. 2, pp. 1-11, Jan. 2011.

[5] C. Honeycutt and S. C. Herring, 'Beyond microblogging: Conversation and collaboration via twitter', Proc. 42nd Annu. Hawaii Int. Conf. Syst. Sci. HICSS, pp. 1-10, 2009.

[6] J. Gordon and S. Berhow, 'University websites and dialogic features for building relationships with potential students', Public Relat. Rev., vol. 35, no. 2, pp. 150-152, Jun. 2009.

[7] J. Dunlap and P. Lowenthal, 'Tweeting the night away: Using Twitter to enhance social presence', J. Inf. Syst. Educ., vol. 20, no. 2, pp. 129-136, 2009.

[8] R. Junco, G. Heiberger, and E. Loken, 'The effect of Twitter on college student engagement and grades', J. Comput. Assist. Learn., vol. 27, no. 2, pp. 119-132, 2011.

[9] L. S. Vygotsky, Mind in society: The development of higher psychological processes. Cambridge, Mass: Harvard University Press, Original manuscripts [ca. 1930-1934], 1978.

[10] B. Short, J., Williams, E., \& Christie, The social psychology of telecommunications. London: John Wiley \& Sons, 1976.

[11] N. Danino and G. Sim, 'TReACLE: A framework for TwitteR analysis in a social and learning environment', in Proceedings of the 28th International BCS Human Computer Interaction Conference: Sand, Sea and Sky - Holiday HCl, HCl 2014, 2014.

[12] M. and D. S. Kanwar, Canadian Sociology. lowa: Kendall/Hunt Publishing Company, 2000.

[13] D. Jacobson, 'Presence Revisited: Imagination, Competence, and Activity in Text-Based Virtual Worlds', CyberPsychology Behav., vol. 4, no. 6, pp. 653-673, 2001.

[14] J. Mavrikis, A., Maciocia, A., Lee, 'Targeting the affective state of students studying mathematics on a webbased ILE', in Young Researchers Track of the 11th International Conference on AIED, 2003.

[15] D. A. Kolb, Experiential learning: Experience as the source of learning and development. Englewood Cliffs, NJ: Prentice-Hall, 1984.

[16] M. Hardey and M. Hardey, 'Conference Notes - The Social Context of Online Market Research: An Introduction to the Sociability of Social Media', Int. J. Mark. Res., vol. 51, no. 4, pp. 562-564, 2009.

[17] L. Lomicka and G. Lord, 'A tale of tweets: Analyzing microblogging among language learners', System, vol. 40, no. 1, pp. 48-63, Mar. 2012.

[18] A. Bryman, Quantity and Quality in Social Research. London: Routledge, 1988.

[19] J. W. Creswell and V. L. P. Clark, Designing and Conducting Mixed Methods Research. Thousand Oaks, CA: Sage Publications, 2011.

[20] F. A. Petitt, 'A comparison of World-Wide Web and paper-and-pencil personality questionnaires', Behav. Res. Methods, Instruments Comput., vol. 34, no. 1, pp. 50-54, 2002.

[21] E. Kouloumpis, T. Wilson, and J. Moore, 'Twitter sentiment analysis: The good the bad and the omg!', Proc. Fifth Int. AAAI Conf. Weblogs Soc. Media (ICWSM 11), pp. 538-541, 2011.

[22] D. Maynard and A. Funk, 'Automatic detection of political opinions in Tweets', pp. 88-99, 2012.

[23] Z. Bagdasarov, A. Martin, R. Chauhan, and S. Connelly, 'Aristotle, Kant, and ...Facebook? A Look at the Implications of Social Media on Ethics', Ethics Behav., vol. 27, no. 7, pp. 547-561, 2017.

[24] S. S. J. Lee, 'Studying "Friends": The Ethics of Using Social Media as Research Platforms', Am. J. Bioeth., vol. 17, no. 3, pp. 1-2, 2017. 
[25] N. Mitchell, N. Danino, and L. May, 'Motivation and manipulation: A gamification approach to influencing undergraduate attitudes in computing', in 7th European Conference on Games Based Learning, ECGBL 2013, 2013, vol. 1. 